\title{
ETNOGRAFIA AUDIOVISUAL: POTENCIAIS E DESAFIOS NA PESQUISA ORGANIZACIONAL
}

\author{
Audiovisual etnography: virtues and challenges for organizational research
}

\author{
Eduardo Paes Barreto Davel ${ }^{*}$ \\ Letícia Dias Fantine|** \\ Josiane Silva de Oliveira ${ }^{\star * *}$
}

\begin{abstract}
RESUMO
O uso audiovisual prefulgura tanto na sociedade contemporânea quanto na prática da pesquisa acadêmica em Ciências Sociais, apesar de ainda não encontrar vigor na pesquisa organizacional. 0 objetivo deste artigo é congregar o conhecimento acumulado sobre a relação entre etnografia e audiovisual com o propósito de contribuir para o avanço das práticas metodológicas de pesquisa em estudos organizacionais. A partir de uma revisão extensiva nas produções sobre essa relação, reunimos, organizamos e sistematizamos a discussão sob o conceito de 'etnografia audiovisual'. Se esta relação é ampla e variada no campo das Ciências Sociais, ela ainda é tímida e inexpressiva no campo dos Estudos Organizacionais. Nesta pesquisa, elaboramos, apresentamos e discutimos dois eixos que nos ajudam a pensar virtudes e desafios da etnografia audiovisual para a pesquisa organizacional: o eixo da integração do audiovisual na etnografia e o eixo da autoria do audiovisual na etnografia. Implicações para pesquisas futuras são formuladas e discutidas.
\end{abstract}

Palavras-chave: Metodologia de pesquisa. Audiovisual. Etnografia. Estudos Organizacionais. Filme Etnográfico.

\begin{abstract}
The uses of the audiovisual irradiate into both the contemporary society and the research pratice of the Social Sciences, although it does not find vigor in the field of organizational research. The goal of this article is to congregate the accumulated knowledge on the relation between ethnography and audiovisual in order to contribute to the advancement of methodological practices wihin organization studies. From an extensive review of academic production on that relation, we regroup, organize and systematize the discussion under the concept of 'audiovisual ethnography'. If that relation is broad and diverse in the field of Social Sciences, it is still limited and inexpressive in the field of organization studies. In this research, we elaborate, presente and discuss two axes that help us to think about the virtues and challenges of audiovisual ethnography for organizational research: the axis of audiovisual integration in ethnography and the axis of audiovisual authorship in ethnography. Implication for further research is formulated and discussed.
\end{abstract}

Keywords: Research methodology. Audiovisual. Ethnography. Organization Studies. Ethnographic film.

\footnotetext{
* Ph.D. em Administração pela École des Hautes Études commerciales de Montreal (Canadá). Professor do Programa de Pós-graduação em Administração e do Centro Interdisciplinar de Desenvolvimento e Gestão Social da Universidade Federal da Bahia (CIAGS e NPGA/UFBA) - Salvador (BA), Brasil. E-mail: davel.eduardo@gmail. com. ORCID: 0000-0003-0610-6474

** Doutora em Administração pela Universidade Federal da Bahia (UFBA). Professora Adjunta do Departamento de Administração e Professora Permanente do Programa de Pós-graduação (Mestrado e Doutorado) em Administração da Universidade Federal do Espírito Santo (UFES) - Vitória (ES), Brasil. E-mail: leticia.fantinel@ufes. br. ORCID: 0000-0002-4589-6352

*** Pós-doutoranda em Administração de Empresas pela Escola de Administração de Empresas da Fundação Getúlio Vargas (FGV- EAESP). Doutora em Administração pela Universidade Federal do Rio Grande do Sul (UFRS). Professora do Programa de Pós-graduação em Administração da Universidade Federal de Goiás (UFG) e Professora do Programa de Pós-graduação em Administração da Universidade Estadual de Maringá (UEM) Maringá (PR), Brasil. E-mail: oliveira.josianesilva@gmail.com. ORCID: 0000-0002-7085-8921
} 


\section{INTRODUÇÃO}

$\mathrm{F}$ otos e vídeos têm sido utilizados no campo da etnografia desde seu surgimento. 0 primeiro filme etnográfico remonta a 1895, quando Felix-Louis Regnault filmou uma mulher senegalesa fazendo cerâmica. Apesar de o filme ter sido utilizado por vários pesquisadores, foram Margaret Mead e Gregory Bateson que inauguraram os métodos da etnografia visual (e.g. fotos e filme) como instrumentos científicos (ROBBENS, 2007). Eles abriram a possibilidade de uso da fotografia e do filme como fonte de informações e como dispositivo analítico de informações. Na década de 1980, os antropólogos visuais demonstraram seu forte interesse pelo uso de vídeo na pesquisa. Na década de 1990, o uso do vídeo alcança o interesse de pesquisadores de outras disciplinas. Assim, o audiovisual é utilizado de forma reflexiva como um meio de gerar conhecimento e não somente informações básicas para a pesquisa.

No campo da Administração, as etnografias ganharam um amplo terreno ao longo das últimas décadas; recentemente, o audiovisual também tem sido utilizado e valorizado pelos pesquisadores. Entretanto, pouco se menciona sobre etnografias audiovisuais no campo da Administração ou dos Estudos Organizacionais. Ora, os estudos visuais da Administração inserem-se na virada visual ocorrida na pesquisa em Administração como contrapeso à virada linguística (BELL; DAVISON, 2013). Trata-se de uma forma de melhor explorar o 'modo visual' do discurso e da construção do sentido, ressaltando o impacto da visualização na prática de pesquisa (MEYER et al., 2013), já extensamente debatido em diferentes campos do conhecimento, no Brasil e no Exterior (BANKS, 1990; CARTA, 2013; CHIOZZI; DRESNER, 1989; COELHO, 2012; CONGDON; NOVACK; GOLDIN-MEADOW, 2018; CORSARO, 1982; FELE, 2002; FERRAZ, 2014; FIJN, 2007; FONSECA, 1998; GILLETTE, 2014; GOODMAN, 2004; GRIMSHAW; RAVETZ, 2015; HINDMARSH; HEATH, 2007; HUTCHISON, 2011; JACKSON JR, 2004; KNOBLAUCH; SCHNETTLER, 2012; LEVIN; CRUZ, 2008; MARKS, 1995; RAKIC, T.; CHAMBERS, 2009; RUBY, 2008; SILVA, 2007). Na pesquisa em Administração, o status do 'visual', que já foi operacionalizado nos Estudos Organizacionais inclusive no Brasil (CAVEDON, 2005), é entendido por meio de cinco abordagens (MEYER et al., 2013): arqueológica (artefatos visuais são o armazenamento de conhecimento social sedimentado); prático (artefatos visuais são objetos materiais e performativos); estratégico (artefatos visuais apresentam efeitos na audiência); dialógico (artefatos visuais são uma forma de comunicação entre o pesquisador e seu campo) e documental (artefatos visuais são uma forma de produzir notas de campo). Apesar do audiovisual ganhar espaço na pesquisa no campo da Administração (CHRISTIANSON, 2018; GYLFE et al., 2016; HEATH; LUFF, 2018; HINDMARSH; LLEWELLYN, 2018; LEBARON et al., 2018; TORALDO et al., 2016), estas pesquisas não são etnografias, nem sobre etnografias, em sua grande parte (JARRETT; LIU, 2018; SLUTSKAYA et al., 2018; SMETS et al., 2014; VESA; VAARA, 2014). Uma das poucas etnografias audiovisuais é a de Liu e Maitlis (2014), realizada no contexto de uma microetnografia, na qual o audiovisual é empregado para registrar reuniões. Ou seja, o horizonte ainda é amplo para nos beneficiarmos das virtudes que as etnografias audiovisuais proporcionam para o campo da Administração e dos Estudos Organizacionais. 
O objetivo deste artigo é congregar o conhecimento acumulado sobre a relação entre etnografia e o universo do audiovisual, esperando que essa integração de conhecimento apresente um método instigante e viável de pesquisa, bem como estimule a realização de etnografias audiovisuais no campo dos Estudos Organizacionais. A reflexão sobre etnografia audiovisual encontra-se em uma teia terminológica em que nomenclaturas se entrelaçam e, muitas vezes, se confundem. Alguns pesquisadores vão se situar na antropologia visual e lidar com filmes etnográficos. Outros vão enfocar a mídia pictorial e, ainda, outros denominarão a comunicação visual como ação inclusiva (RUBY, 2005). Visual pode significar cada um desses assuntos isoladamente ou a mistura deles.

Em suma, o campo conceitual da relação entre etnografia e audivisual é polissêmico. Fala-se de vídeo etnográfico (AARSAND; FORSBERG, 2010; PINK, 2007), filme etnográfico (ALTMANN, 2009), etnografia vídeo-reflexiva (COLLIER; WYER, 2016; COLLIER et al., 2015; HOR et al., 2014; CARROL et al., 2008), etnografia multimodal (DICKS et al., 2006), filme etnográfico transcendente (FALZONE, 2004), etnografia virtual (HINE, 2000, 2015), etnografia digital (MURTHY, 2008; PINK et al., 2016), etnografia visual (PINK, 2007), etnografia de vídeo (SHRUM; SCOTT, 2017), etnografia experimental (RUSSELL, 1999), etnografia de perspectiva participativa (WILHOIT; KISSELBURGH, 2016). Neste artigo, não vamos nos prender nas distinções entre esses vários conceitos, mas buscar combinar suas forças e singularidades para pensar em um conceito integrador, que denominaremos de 'etnografia audiovisual'. Por outro lado, a etnografia virtual ou digital - que enfoca o estudo da vida social online - não é foco desta pesquisa, apesar de também ganhar uma significativa discussão (KELTY, 2008; COLEMAN, 2010, 2012; BOELLSTORFF, 2008; BOELLSTORFF et al., 2012; WESCH, 2009; WHITEHEAD; WESCH, 2009; CASE, 2012; YORK, 2012).

Para produzir esse artigo, realizamos uma revisão sistemática de produções acadêmicas publicadas nas bases de dados nacionais e internacionais (SPELL, SCIELO, Sage Publications, Routledge, Periódicos CAPES, Library of Congress, Emerald, Academy of Management). A partir de uma primeira etapa de seleção (produções consistentes e coerentes, tratando da relação entre etnografia e audiovisual) e análise desse material, mapeamos suas referências bibliográficas na busca de outras produções relevantes. Ou seja, o processo de revisão ocorreu dentro de uma dinâmica de bola de neve, que chegou a um fim quando nenhuma referência emergia como nova e relevante. A partir da análise sistemática de todas as produções selecionadas, desenvolvemos e propomos dois eixos para pensarmos e aplicarmos a etnografia audiovisual no campo da Administração e dos Estudos Organizacionais:

(a) Eixo de integração do audiovisual na etnografia:

- Pólo de integração processual - a etnografia é mediada pela coleta de informações audiovisuais, mas seu resultado toma a forma de um produto textual tradicional (e.g. artigo, livro), podendo se valer de algumas representações visuais como fonte de ilustração.

- Pólo de integração integral - a etnografia é mediada pela coleta de informações audiovisuais e seu resultado toma a forma de um produto audiovisual (e.g. filme etnográfico).

(b) Eixo de autoria do audiovisual na etnografia: 
- Pólo de participação não-autoral dos pesquisados - a etnografia é centralizada no âmbito do pesquisador e conta com uma colaboração inexpressiva dos pesquisados (participantes na pesquisa) para com o processo e resultado da pesquisa.

- Pólo de participação autoral dos pesquisados - a etnografia é compartilhada entre pesquisador e pesquisados (participantes na pesquisa), nas suas várias dimensões, produções e etapas.

Cada eixo proposto é estruturado a partir de dois pólos. Todavia, não se trata de duas possibilidades dicotômicas (um ou outro), mas sim de gradações e variações. Ou seja, na prática de pesquisa, poderemos encontrar graus variados de combinação de elementos dos dois pólos, gerando possibilidades mistas de aplicação metodologica da etnografia audiovisual na prática da pesquisa.

\section{A INTEGRAÇÃO DO AUDIOVISUAL NA ETNOGRAFIA AUDIOVISUAL}

O eixo da integração do audiovisual na etnografia audiovisual é composto de depois pólos: processual ou integral. No polo processual, encontramos a versão mais leve da etnografia audiovisual, na qual o pesquisador se utiliza do material empírico e da experiência audiovisual para desenvolver o conhecimento, mas o resultado da pesquisa é confecionado na forma de texto escrito. No polo processual, a etnografia é mediada pela coleta de informações audiovisuais, pela análise e interpretação dessas informações, mas seu resultado toma a forma de um produto textual tradicional (por exemplo, um artigo, um livro), podendo se utilizar de alguns dados visuais como fonte de ilustração. Já no polo integral, o pesquisador se utiliza do material empírico e da experiência audiovisual para desenvolver o conhecimento, mas o resultado da pesquisa também se expressa no formato audiovisual (filme ou vídeo etnográfico).

\subsection{AUDIOVISUAL COMO FONTE DE INFORMAÇ̃̃O: A INTEGRAÇÃO PROCESSUAL DO AUDIOVISUAL NA ETNOGRAFIA}

\subsubsection{Usos e práticas do material audiovisual}

O audiovisual como fonte de informação. Etnografias audiovisuais referem-se ao uso de tecnologias de registro para gravar imagens em movimento com som. Essas imagens revestem-se de maior complexidade do que as imagens estáticas. A compreensão da vida social é um processo que acontece no decorrer do tempo. A melhor forma de coletar e comunicar informações não estáticas ocorre pelos registros audiovisuais. Na etnografia audiovisual, o registro audiovisual é uma fonte rica de informação, requerendo que o pesquisador transcenda a divisão entre imagem e texto etnográfico e que considere a visão como dispositivo crítico na produção de conhecimento (GRIMSHAW, 2001). O registro audiovisual nos permite saber sobre atmosferas, como elas são produzidas e sentidas pelas pessoas 
nos momentos cotidianos, gerando formas empáticas, sensoriais e afetivas de engajamento (PINK et al., 2014)

O registro audiovisual como recurso para a observação participante vem se difundindo em diferentes campos e perspectivas da pesquisa social (BASIL, 2011) Ele permite armazenar e representar as informações a serem analizadas (DICKS et al., 2006), tais como comportamentos e rituais em contexto (favorecendo sua reflexão, informação e codificação) e a análise de ambientes específicos (BASIL, 2011). Entretanto, registros também incluem outros tipos de materiais audiovisuais. Filmes também podem se transformar em fonte de informação para o etnógrafo (GARRETT, 2010), haja vista que podem ser analizados como informação de pesquisa na forma de narrativas processuais para melhor compreendermos comportamentos organizacionais e desenvolver teorias (HASSARD; BUCHNAN, 2009). Trata-se de obras artísticas que revelam representações culturais, tranduzindo consciências coletivas e imaginários das sociedades situadas espaço-temporalmente no contexto em que são produzidas. Nesse sentido, os filmes como registros audiovisuais, permitem descortinar pensamentos e representações circulantes no que tange a vários e diversos aspectos sociais.

Os registros audiovisuais permitem documentar um contexto estudado e ser analisado repetidas vezes, promovendo múltiplas interpretações. Para além da documentação, preservação e disponibilização de registros de determinados contextos espaço-temporais, seja para pesquisadores ou não, o audiovisual pode ser utilizado como material de análise detalhada de diferentes elementos, como ritmos de interação social, materialidades e artefatos, ou mesmo formas de comunicação não verbal, a exemplo de gestos e linguagem corporal, dificilmente captadas conscientemente no fluxo da pesquisa (GARRETT, 2010).

Etnografias audiovisuais podem produzir e comunicar conhecimento sobre culturas (ALFONSO et al., 2004), gerando uma compreensão etnográfica (HENLEY, 2000) em escala mais focada ou ampliada. O pesquisador pode realizar uma etnografia audiovisual focada nas interações em escala micro-social, sob a denominação de micro-etnografia (ERICKSON, 1982). Nesta escala, o enfoque recai sobre o estudo minucioso dos comportamentos verbais e não verbais, como eles ocorrem nas interações sociais imediatas em encontros face a face. A escala ampliada da etnografia engloba preocupações mais tradicionais com um contexto mais amplo e a produção de sentido nesse contexto.

Globalmente, o registro audiovisual permite uma sofisticação na representação, na medida em que potencializa o desvendamento da fluidez e do ritmo da experiência humana. Esse tipo de registro é capaz de capturar fluxos cotidianos sob diferentes óticas, como a do pesquisador e a do pesquisado (GARRETT, 2010). Não obstante, os usos do vídeo propiciam a produção de documentos culturais densos e ricos essenciais ao fazer etnográfico.

Entretanto, o registro audiovisual ultrapassa a simples representação da realidade. Longe de um registro neutro ou objetivo, o audiovisual instiga uma reflexão sobre os efeitos performativos que os diferentes modos de conduzir a pesquisa em vídeo trazem ao processo de investigação (MENGIS et al., 2016) Questões que podem parecer meramente técnicas, como combinações de ângulo e movimento de câmera, podem refletir sensibilidades teóricas e crenças paradigmáticas. Na etnografia audiovisual, cada aparato e movimento pode privilegiar determinadas compreensões espaciais, orientando o olhar para elementos analíticos específicos. 0 uso de uma câmera panorâmica, por exemplo, pode dificultar a análise do espaço como experienciado, uma vez que a filmagem não capta as práticas discursivas das 
pessoas no espaço, diferentemente de outros tipos de posicionamento e angulação, como no caso de uma câmera de movimentação manual, ou acoplada à cabeça do praticante (cujo uso é difundido na videografia de ação e esportes radicais).

O registro audiovisual pode ser produzido pela prática do vídeo shadowing, que consiste no registro audiovisual dos pesquisados durante a realização de suas atividades cotidianas (ISAACS; SZYMANSKI, 2013). É também possível registrar por meio de diários audiovisuais, que são posteriormente transcritos e analisados em suas várias dimensões: textual, áudio e vídeo (ZUNDEL et al., 2016). Diários audiovisuais consomem menos tempo do pesquisador e possibilitam a produção de registros mais fidedignos às narrativas dos pesquisados, considerando o fluxo espontâneo da narrativa oral em comparação à escrita.

MacDougall (1978) estabelece uma distinção entre filmagens etnográficas (ethnographic footage) e filmes etnográficos (ethnographic films). Filmes seriam trabalhos estruturados, produzidos para uma apresentação ou audiência, que engendram em seu conteúdo a análise em si, análogos aos escritos tornados públicos de um pesquisador. Já as filmagens etnográficas, por outro lado, configuram-se como a matéria-prima da análise etnográfica, mais bem comparadas às notas de campo do pesquisador, podendo ser usadas para diversos propósitos, inclusive a própria realização de filmes. No polo de integração processual do audiovisual na etnografia, o pesquisador produz e mobiliza filmagens etnográficas.

O audiovisual como suplemento a notas de campo, ilustração e mediação. Além de seu papel central como fonte rica e densa de informação, o registro audiovisual pode ser mobilizado como um suplemento às notas tradicionais de campo. Pode, também, ser mobilizado como fonte de ilustrações, no intuito de exemplificar determinados fenômenos para leitores e/ou espectadores (BASIL, 2011) Outro uso do audiovisual na etnografia é o de mediação, em que o audiovisual atua como estímulo durante a condução da pesquisa (elicitação). Isso ocorre quando o pesquisador exibe materiais audiovisuais aos pesquisados para buscar suas interpretações e explicações sobre certos fenômenos. Com isso, é possível examinar a compreensão dos informantes sobre determinados eventos. Além de artefatos da cultura material, fotos e filmes também servem como motivadores de discussão. A provocação audiovisual é um aspecto metodológico importante nas histórias digitais e na filmagem participativa. A estratégia de provocação audiovisual refere-se ao uso de entrevistas ou grupos focais para discutir imagens geradas pelo pesquisador, pelos participantes ou em arquivos (BANKS, 2007). Todas essas práticas promovem uma produção rica de informações para o desenvolvimento da etnografia audiovisual.

O audiovisual como conhecimento técnico. A etnografia audiovisual requer algum grau de conhecimento específico relativo ao campo técnico do universo audiovisual. É necessário se planejar e pensar em temas, em pessoas e eventos para filmar. 0 enfoque é descobrir e circunscrever o que acontece com pessoas e situações. É necessário isolar alguma parte do universo social e obter acesso a pessoas e eventos que ocorrerão. Pessoas, redes, eventos, histórias, experiências, práticas, coisas, relações, mundos sociais, localidades são categorias que podem ser mobilizadas para facilitar o processo de pesquisa (PINK et al., 2016; SHRUM; SCOTT, 2017).

A etnografia audiovisual requer algumas estratégias para abordar oportunidades, limites e tomar decisões. Como podemos encontrar e filmar sobre um tema? Como podemos 
administrar a filmagem do evento? Como devemos trabalhar com os participantes? Quando seria melhor filmar? Em um momento do planejamento da pesquisa, será necessário refletir sobre o tipo de câmera para filmar, os espaços de memória, as condições de captação de áudio e iluminação, bem como outros acessórios como baterias, carregadores, fones de ouvido etc. Algumas técnicas básicas de filmagem podem ser de grande valia para que o planejamento metodológico seja refinado e adequado: tipo de enfoque (distância entre a câmera e a pessoa que se filma, podendo aparecer mais contexto, em uma perspectiva ampla, ou, no outro extremo, um foco do rosto, em seus detalhes expressivos), o enquadramento, o ângulo (de cima, de baixo, de lado, no mesmo nível), o movimento da câmera (reconhecimento da cena, pesseando com a câmera, travelling óptico, B-Roll, pedestal etc.), o armazenamento e a classificação dos arquivos.

O audiovisual como negociação e relação ética. A produção audiovisual na etnografia é uma atividade mais intrusiva se comparada a outras formas de pesquisa de campo. Por isso, ambiguidades nas relações de poder entre pesquisador e pesquisado podem ficar mais evidentes nesses processos de produção. 0 pesquisador que atua em campo com um bloco de notas pode fazer anotações e depois decidir o que fazer com elas, enquanto aquele que trabalha com audiovisual precisará negociar, de forma minuciosa, o que e como filmar. 0 nexo de relações que permeiam a produção audiovisual tende a ser mais evidente do que o nexo na produção textual, uma vez que, para obter o consentimento dos pesquisados, o pesquisador será demandado a representar suas visões particulares, motivo pelo qual eles ocuparão um lugar proeminente na versão final do filme etnográfico (HENLEY, 2000).

A produção de etnografias audiovisuais é regida pela ética de pesquisa que envolve respeito aos princípios de privacidade, anonimato, confidencialidade, consentimento livre e esclarecido em relação a coleta e difusão de informações sobre seres humanos. Todavia, pesquisadores são confrontados com diversos dilemas sobre como produzir materiais audiovisuais de maneira eticamente responsável. Dilemas éticos podem estar relacionados a normas culturais do grupo pesquisado, ao relacionamento estabelecido com os participantes, a expectativas nutridas por estes em relação ao próprio processo de pesquisa, entre outros fatores (AARSAND; FORSBERG, 2010). Contudo, não é apenas durante a elaboração do vídeo que as preocupações éticas aparecem. Tanto na fase de entrada e acesso ao campo, bem como nos estágios finais da pesquisa, é necessário que o pesquisador tenha em mente as implicações éticas das escolhas feitas durante a investigação (AARSAND; FORSBERG, 2010).

O observador e a tecnologia utilizada na observação, seja ela uma câmera ou um bloco de notas, não se separam do fenômeno pesquisado, devendo ser vistos ontologicamente como partes dele, produzindo, além do fenômeno em si, os próprios observadores, os instrumentos de pesquisa e os objetos da investigação (AARSAND; FORSBERG, 2010).

É fundamental pensar a condução da pesquisa com uso de material audiovisual, considerando-se os riscos, danos, e a própria exposição dos pesquisados ao participar do estudo (PINK, 2001). Algumas preocupações devem orientar o pesquisador: (a) solicitar e obter consentimento de indivíduos e grupos para a captação de imagens, (b) demonstrar cuidado constante em não causar danos aos pesquisados, (c) esclarecer os pesquisados a respeito das intenções da pesquisa, (d) fornecer a devolutiva e contribuição da pesquisa ao coletivo pesquisado (de forma que o fluxo de informações na etnografia não ocorra apenas 
em uma via), e (e) discutir com os pesquisados sobre a questão da propriedade dos materiais oriundos da pesquisa. As questões de propriedade podem se tornar complexas se a pesquisa for financiada por instituições ou produzida em colaboração com os pesquisados.

Em todo momento da pesquisa, a reflexão ética é acentuada pelo caráter invasivo do audiovisual. Para além de preocupações básicas como a manutenção da privacidade e do anonimato (quando necessário) dos pesquisados, algo dificultado no uso de vídeo em pesquisa (BLACK, 2017), é importante o questionamento quanto a aspectos mais específicos, como particularidades do grupo pesquisado ou a construção da própria narrativa fílmica. Com efeito, o posicionamento do etnógrafo em todo processo de pesquisa, bem como a relevância da pesquisa para os sujeitos pesquisados, são aspectos éticos cruciais a serem dialogados e explicitados (ASCH, 1992).

Audiovisual no universo digital. Etnografias audiovisuais podem ser confundidas com etnografias digitais. Apesar de não representarem exatamente o mesmo tipo de etnografia, entendemos que os registros audiovisuais se encontram em ambiente digital. Assim, o etnógrafo audiovisual deve considerar o intangível como parte da pesquisa, pois entende o intangível digital na relação entre elementos digitais, sensoriais, atmosféricos e materiais em nosso mundo social (PINK et al., 2016). Ou seja, o foco recai sobre como o audiovisual e o digital se tornaram parte dos mundos materiais, sensoriais e sociais em que vivemos, e como isso repercute na prática de pesquisa etnográfica. Além disso, alguns princípios podem ser destacados, quando a etnografia audiovisual é pensada no âmbito digital (PINK et al., 2016): multiplicidade (existe mais de uma forma de se engajar com o digital), descentralidade (o digital é descentralizado na etnografia), abertura (a etnografia é um evento aberto), reflexividade (a etnografia envolve a prática reflexiva) e não ortodoxo (a etnografia requer atenção para formas alternativas de comunicação).

\subsubsection{Análise e interpretação do material audiovisual}

O audiovisual como construção densa. Os registros audiovisuais concentram uma diversidade de informações, tornando o processo de análise e interpretação uma atividade rica. No processo operacional da análise de registros audiovisuais, a hierarquia entre imagens e palavras se desfaz, para enfocar conteúdo e contexto, considerar os significados locais e etnográficos (PINK, 2001) 0 pesquisador durante o processo de análise tende a organizar o material de forma sequencial e a privilegiar narrativas autênticas e nativas.

O filme etnográfico expressa uma 'inscrição densa' de pessoas e acontecimentos, na medida em que pode fornecer a base para futuras reinterpretações, em uma dimensão e escala muito mais intensiva e densa do que o texto escrito (HENLEY, 2000) 0 próprio processo de produção do texto e do filme seguem caminhos opostos. Enquanto a escrita geralmente representa um processo de expansão e elaboração decorrente das notas de campo, a edição de um filme representa um processo de síntese e redução. Nesse sentido, o pesquisador é encorajado a selecionar muito mais cuidadosamente o que será representado no filme.

O princípio da construção. O processo de análise deve ser pautado na lógica em que o audiovisual é considerado como construção social e subjetiva. Ou seja, as informações 
capturadas em registros audiovisuais não documentam de forma objetiva uma realidade externa ao pesquisador (BASIL, 2011). O registro audiovisual deve ser considerado, portanto, como um meio de representação, envolvendo um processo social e subjetivo de construção. Assim, compreendemos que, ainda que duas ou mais pessoas filmem os mesmos objetos ou situações, elas não o farão da mesma forma, evidenciando interpretações e desvendamentos heterogêneos. Com efeito, tais representações são construídas: sua interpretação conferida pelo pesquisador e pela audiência carregam determinados valores, crenças e ideologias (BASIL, 2011). Ainda que representações objetivas fossem possíveis, elas não seriam consumidas objetivamente, uma vez que todos os meios audiovisuais são construções trianguladas entre a subjetividade de quem filma, a de quem é filmado e a do espectador (GARRETT, 2010). Cabe, portanto, compreender o vídeo como representação e não como o mundo real em si (DICKS et al., 2006).

Filmar é uma forma de anotar. Todavia, o pesquisador deve afastar a concepção inocente de que a gravação audiovisual revela a realidade, tornando desnecessário o trabalho reflexivo e interpretativo. A reflexividade é uma marca importante do processo metodológica das pesquisas qualitativas contemporâneas (ALVESSON; SKÖLDBERG, 2000). Nesse sentido, nos distanciamos do audiovisual como uma realidade 'objetiva' e nos aproximamos da noção do audiovisual como representação construída pelas perspectivas de seus produtores e públicos, que encorajam o desenvolvimento de abordagens colaborativas para a produção e interpretação de produções audiovisuais (PINK, 2001).

O registro audiovisual pode ser compreendido como uma prática material-discursiva (AARSAND; LUCAS, 2010). Assim, as formas materiais de conduzir uma pesquisa baseada em audiovisual podem acarretar um efeito performativo no objeto de pesquisa, ultrapassando a perspectiva de simples registros de fenômenos sociais (MENGIS et al., 2016). Nesse sentido, o uso do audiovisual em diferentes etnografias levanta reflexões relevantes sobre o papel e a influência do pesquisador, na medida em que, ao intervir no processo de filmagem e edição, o pesquisador não apenas registra, mas também intervém, na medida em que produz descrições e interpretações (ZUNDEL et al., 2016) sobre o campo de pesquisa. No campo da Administração, Bell e Davison (2013) ressaltam que o uso de métodos audiovisuais deve ser pensado para além de pressupostos realistas. Registros audiovisuais são mais do que simples meios técnicos de coletas de dados. Ultrapassando a operacionalização de um conjunto de ferramentas, a mobilização de materiais audiovisuais requer uma visão distinta de mundo e de processo da pesquisa.

0 princípio da co-construção reflexiva. Para pensarmos a produção reflexiva de audiovisual, partimos da premissa de que os registros de filmagem, edição e divulgação de vídeos (frutos de trabalhos de pesquisa) podem ser frutos tanto de eventos testemunhados como de experiências de produção (GARRETT, 2010). Sua importância não reside somente em seu conteúdo, mas também no subtexto, quase imperceptível, que revela os ditos e não ditos na produção do pesquisador. Garrett (2010) destaca que essa análise dos subtextos, presentes na produção científica audiovisual, aproxima-se do potencial do chamado cinema reflexivo, que valoriza questões que versam sobre quem está por trás da câmera, as decisões sobre para onde apontá-la, o processo de edição etc. Pensar a subjetividade inerente à produção do material audiovisual, portanto, abre-se como potencial analítico e reflexivo na prática da etnografia audiovisual. Nesse sentido, a análise e interpretação dentro de uma etnografia audiovisual pode ser um processo de co-construção (compartilhada com 
os pesquisados) que se dinamiza em torno de atividades reflexivas de ambas as partes: pesquisadores e pesquisados.

Por exemplo, a produção de vídeos colaborativos possibilita aos pesquisados articularem, em seus próprios termos, suas percepções e discursos, bem como o que desejam transmitir. Com isso, os processos de análise, interpretação, edição e produção se tornam compartilhados e co-construídos (GARRETT, 2010). Mesmo que o pesquisador empreenda esforços para permanecer fiel à voz de seus informantes no texto, a palavra escrita sempre contará com a mediação da subjetividade de quem a produz. Além disso, a interação que decorre dos processos de produção dos vídeos permite uma maior aproximação com os pesquisados na busca por suas interpretações de imagens e sons produzidos, cotidianamente, no fluxo de suas experiências. Dentro da pesquisa etnográfica, compartilhar a produção audiovisual pode ajudar a partilhar a autoria do fazer etnográfico em si, permitindo aos pesquisados escolherem o que preferem incluir e excluir das narrativas (GARRETT, 2010). Isso aproxima pesquisados e pesquisadores, instaurando uma ressignificação de concepções de autoridade acadêmica e de agência na pesquisa.

\subsection{AUDIOVISUAL COMO RESULTADO DA PESQUISA: A INTEGRAÇ̃̃O INTEGRAL DO AUDIOVISUAL NA ETNOGRAFIA}

A etnografia audiovisual pode integrar o audiovisual de maneira total, ou seja, não somente mobilizar o audiovisual no processo de pesquisa (coleta de dados, análise dos dados), mas também ser a linguagem privilegiada para difusão dos resultados. Nesta seção, destacamos formas de uso do vídeo na pesquisa social que, sob o signo do fazer etnográfico, é denomidado também de 'videografia' (ERICKSON, 2011) ou 'filme etnográfico' (MACDOUGALL, 1978). Tal prática corresponde à elaboração de documentários editados, cujo desenvolvimento se dá a partir de relatos narrativos, videográficos e etnográficos. Não se trata da simples utilização do audiovisual como base para a análise e interpretação, com fins de elaboração posterior de um relato etnográfico escrito. 0 registro audiovisual é o próprio relato, ainda que possa ser utilizado de forma conjunta com textos escritos para fornecer narrativas etnográficas mais completas, finas e abrangentes (HENLEY, 2000).

No campo da Antropologia, a produção de filmes etnográficos, apesar de iniciar-se ainda no século XIX, foi pouco mobilizada, tanto no ensino como na pesquisa ao longo do século XX, com algumas notáveis exceções (HENLEY, 2000). No Reino Unido, filmes etnográficos foram realizados ao longo do tempo, com foco no trabalho e em instituições, desde a década de 1930, sob vários estilos de filmagem: 'filme do mundo do trabalho', 'filme do cinema livre', 'documentários da televisão moderna' e 'vídeo diários e blogs' (HASSARD, 2009). Ainda que constatemos certo entusiasmo com relação ao filme etnográfico, durante muito tempo, ele recebeu a reputação de uma atividade cara, tecnicamente complexa e que toma muito tempo, além de algo que dificilmente seria levado a sério no meio científico, fortemente ancorado no poder das palavras.

Em revanche, o filme etnográfico foi mudando ao longo dos tempos, apresentando várias inovações em relação a tecnologia de produção, ao assunto enfocado, as estratégias argumentativas e a autenticação etnográfica (LOIZOS, 1993). Com os avanços tecnológicos drásticos, as facilidades se tornam incessantes e popularizadas na forma de registrar por 
meio do audiovisual. Essas facilidades e inovações geram um debate sobre questões como realismo, autenticidade, gênero, vozes autorais e subjetivas (LOIZOS, 1993). Assim, o filme etnográfico se situa novamente com um caminho desejado e relevante de realizar e promover etnográficas audiovisuais na contemporaneidade.

A partir da década de 1980 algumas viradas teóricas vêm tornando o meio científico mais receptivo a produções audiovisuais no âmbito etnográfico (HENLEY, 2000). Por exemplo, a ascensão de abordagens pós-modernas e interpretativas tende a favorecer uma atitude mais aberta em relação aos benefícios potenciais do filme etnográfico. Essa ascenção estimula a ampliação de foco, que antes se limitava na descrição de casos etnográficos particulares, para incluir uma concepção da dinâmica processual da vida social, da polifonia, do repensar a chamada autoridade etnográfica, entre outros. Ao passo que a pesquisa etnográfica redireciona suas atenções para dimensões corporificadas e singulares da vida cotidiana (em detrimento das estruturas subjacentes e outras abstrações), abre-se um maior espaço para a produção e recepção de representações audiovisuais em seu seio (HENLEY, 2000).

Como resultado de uma etnografia audiovisual, o filme etnográfico tem capacidade significativa de proporcionar a representação multissensorial, operarando em pelo menos dois dos cinco sentidos, ao mesmo tempo. Por exemplo, o filme opera na representação de lugares, culturas, grupos sociais, movimentos, ritmos e fluxos (GARRETT, 2010). Trata-se de uma capacidade que favorece o incremento da sensação ao espectador de 'estar lá', de 'se sentir lá', algo pretendido no fazer etnográfico enquanto experiência incorporada. Com efeito, o filme etnográfico constrói-se como um meio de recordar e relacionar experiências de campo com aqueles que não estavam presentes no momento da produção das informações. Ele responde à necessidade crucial de apresentar 'atos completos', 'corpos completos', 'interações completas' e 'pessoas completas', preservando a integralidade do contexto cultural (HEIDER, 2006).

No início da década de 1990, filmar e editar não era fácil. Nos tempos atuais não conseguimos imaginar muitas dificuldades em gravar, codificar e analisar, não vislumbrando possibilidades de outros meios mais atraentes de apresentar e visualizar os resultados da pesquisa. Filmar e fazer um filme para os pesquisadores contemporâneos é atividade mais simples. Se podemos escrever, podemos fazer um filme. Editar é um termo que escritores utilizam para falar do que precisa ser feito depois de escrever. Então, é surpreendente que editar significa, também, escrever um filme, mas com imagens e sons, ao invés de palavras. 0 processo é relativamente similiar, tanto para redigir um artigo acadêmico quanto para editar um filme. Todavia, se fazer um filme é atividade simples, isso não significa dizer que é simples fazer um bom filme, assim como não é fácil fazer um bom artigo acadêmico.

Quando o objetivo é integrar o audiovisual plenamente no processo da etnografia audiovisual, a atividade de edição audiovisual se torna uma atividade estratégica para o pesquisador. Editar é um processo central que requer conhecimento do aplicativo de edição e dos princípios gerais de como editar. São princípios de categorização, organização por meio de introdução, problemática, argumento e conclusão. Editar envolve organizar o material em vários componentes (videoclipes, arquivos de áudios, fotografias etc.), categorizando os componentes em temas, desassociando e reassociando audio com imagem, cuidando das transições (visuais e sonoras) e dos efeitos (estabilização, velocidade etc.), tudo isso 
dentro de uma linha cronológica para produzir a história com a narrativa desejada (SHRUM; SCOTT, 2017).

Outra atividade chave no processo de realização de um filme etnográfico é a divulgação. Cameras, arquivos, sistemas de edição são aspectos técnicos importantes do movimento da etnografia audiovisual, assim como os aspectos sociais de filmagem, que fazem emergir relações de participação e expressões ativistas de todos envolvidos. Todavia, a relação com os pesquisados é considerada a mais determinante (SHRUM; SCOTT, 2017). Quando as pessoas envolvidas perceberem que serão filmadas, editadas e distribuidas na forma de um filme sobre elas, isso muda todo processo. Muda para melhor. Em um primeiro momento da relação, houve a troca de capacidades técnicas (do pesquisador) pelo acesso a situações socioculturais (dos pesquisados). Depois de editar e produzir um filme é necessário mostrar os resultados aos informantes e estabelecer um diálogo que permitirá fazer refinamentos e ajustes necessários (SHRUM; CASTLE, 2014). Na sequência, filmes etnográficos podem ser submetidos e apresentados em conferências e revistas acadêmicas, com maior grau de especialidade ou não no assunto. Por exemplo, podemos encontrar algumas conferências e revistas especializadas, como o Ethnografilm Festival (http://www. ethnografilm.com) e o Journal of Video Ethnography (http://www.videoethno.com).

Se o filme etnográfico se apresenta na contemporaneidade como desejável e relevante, por outro lado, muitos desafios ainda existem. Por exemplo, alguns pesquisadores consideram que o filme etnográfico proporciona uma descrição leve (registro de uma forma de comportamento) em relação as descrições densas (relato detalhado de sentido) (CRAWFORD; TURTON, 1992). O estatuto mimético da imagem pode explicar a desconfiança dos antropólogos em relação a filmes etnográficos, na medida em que uma grande parte dos pesquisadores pressupõem que a percepção visual, por si só, é limitada e superficial (ALTMANN, 2009). Além disso, existe uma forte tradição de pesquisa atrelada ao uso do verbal em detrimento ao do imagético. Isso limita a atuação de pesquisadores, não apenas, metodologicamente, mas inclusive em termos de divulgação de suas publicações (BASIL, 2011).

Outro desafio importante refere-se aos meios de difusão acadêmica: poucos periódicos mostram-se abertos e disponíveis à publicação de materiais audiovisuais decorrentes de investigações científicas. Essa raridade de periódicos científicos preparados e receptivos à submissão e publicação de materiais audiovisuais representa parte da dificuldade de apropriação por parte dos pesquisadores de produções audiovisuais enquanto formas de legítimas de produção acadêmica (GARRETT, 2010). Resistências na consideração de produções audiovisuais como produto legítimo de pesquisa podem revelar reminiscências da tradição positivista e objetivista, que considera a produção audiovisual como dado bruto, ou seja, como mero registro ou documentação científica, a ser transcrito ou transmutado em texto.

Além disso, o pesquisador pode se deparar com desafios relacionados aos direitos autorais da produção audiovisual, às limitações técnicas dos pesquisadores e às dificuldades de distribuição e controle da obra. Com efeito, existem requisitos técnicos necessários ao manuseio ou condução da produção de materiais audiovisuais. Muitos pesquisadores podem pressupor que o recurso audiovisual é muito exigente em termos técnicos, demandando uma formação especializada (GARRETT, 2010). 


\section{A AUTORIA DO AUDIOVISUAL NA ETNOGRAFIA AUDIOVISUAL: 0 GRAU DE ENVOLVIMENTO DOS PESQUISADOS NA AUTORIA DA NARRATIVA ETNOGRÁFICA}

A autoria dos pesquisados na etnografia audiovisual encontra-se situada entre dois polos: não-autoral ou autoral. O polo não-autoral significa que a etnografia é centralizada na posição do pesquisador e conta com uma colaboração inexpressiva dos participantes no processo de pesquisa (coleta de informações, análise e interpretação) e seu resultado, seja ele na forma de um documento textual ou audiovisual (filme etnográfico). Em contrapartida, o polo autoral envolve, de forma mais intensa, variada e sistemática, os pesquisados no processo de pesquisa e produção de seus resultados. Ou seja, a etnografia é compartilhada entre pesquisador e participantes, nas suas várias dimensões, produções e etapas.

Nas etnografias audiovisuais é preciso considerar que os filmes não são simples produtos de informações produzidas durante a pesquisa de campo ou imagens que representam as experiências culturais. Eles são partes de um processo da pesquisa, portanto devem ser compreendidos a partir da dinâmica de construção das relações com os sujeitos de pesquisa, o campo e os 'leitores' dessa produção. Assim, as pesquisas em etnografias visuais têm apresentado, de forma geral, dois caminhos de abordagem dos filmes etnográficos. O primeiro se caracteriza por uma abordagem centralizada no trabalho do etnógrafo, sendo este quem delimita a forma, a realização e o resultado dos filmes etnográficos. Já as abordagens participativas e colaborativas enfatizam a participação dos pesquisados na construção da etnografia visual, desde a concepção do objeto etnográfico até o processo de comunicação da produção audiovisual. Nas 'metodologias visuais participativas', o termo 'participativa' significa que a participação dos membros da comunidade é ativamente integrada na construção do conhecimento (GUBRIUM; HARPER, 2013, 2015).

Autoria como processo de descentralização. Mesmo que os pesquisados não tenham protagonismo na autoria da elaboração dos resultados e do processo da pesquisa, o etnógrafo audiovisual deve repensar sua relação de autoria a partir de uma desconstrução da sua centralidade monológica, reconhecendo outras vozes na construção da narrativa fílmica. O filme etnográfico requer uma sensibilidade do pesquisador para considerar vozes e olhares múltiplos: dos narradores, dos autores, dos receptores. O filme etnográfico não cobre o fato social em sua totalidade, mas reconhece a dimensão artística da prática cinematográfica, que enriquece a dimensão científica da etnografia. Textos e filmes etnográficos são produções humanas que ultrapassam um sentido simples de restituição, registro ou comprovação, para congregar retórica e arte em um mesmo processo (ALTMANN, 2009).

A descentralização da autoria refere-se ao fato de que o pesquisador não detém uma autoridade portadora de verdade pura. Quanto mais a autoridade de produção dos materiais audiovisuais em pesquisas etnográficas for atribuída exclusivamente aos pesquisadores, maior será a centralidade do pesquisador na construção do trabalho de campo e de sua 'autoridade etnográfica' (CLIFFORD, 2008). Todavia, a desconstrução da centralidade dessa autoridade possibilita o reconhecimento de estratégias e polifonias das narrativas que refletem contradições, ambiguidades e interações culturais do trabalho de campo. A desconstrução abre caminho para ampliar a compreensão das sutilezas do campo.

A desconstrução da autoridade do pesquisador requer revisão da ideia de que o pesquisador capta a verdade ao filmar uma cultura durante um trabalho de campo baseado 
em uma observação participante de longa duração. A tendência é que o pesquisador construa estratégias narrativas do audiovisual de forma a explicitar uma perspectiva teórica-disciplinar que assegure uma ordem verídica determinada (ALTMANN, 2009). Esse é um dos procedimentos para que os pesquisados se mostrem como 'verdadeiros', comprovando os fatos sociais filmados e consolidem a autoridade do autor-pesquisador. A descentralização do pesquisador na construção do filme etnográfico implica a desconstrução dessa noção de autoria. Descentralizar significa aceitar que o ponto de vista do etnógrafo não é um fato social objetivo e requer reflexão sobre seu papel tanto durante o registro audiovisual, quanto durante a produção da narrativa fílmica. Descentralizar significa aceitar as polifonias de interpretação durante o trabalho de campo e romper com a autoridade monológica que orienta a produção audiovisual do trabalho etnográfico para um único grupo de leitores ou de 'audiências' (CLIFFORD, 2008). Assim, a descentralização da autoria envolve a 'audiência' na produção de material audiovisual.

Há possibilidade de reconhecimento de outras vozes na construção das narrativas filmícas, bem como o entendimento de que a dimensão audiovisual vai além da representação da dinâmica do trabalho de campo. Esta dimensão é resultado das interações do trabalho de campo e permite diferentes leituras sobre sua produção. A escolha dos eventos que constroem as produções audiovisuais, assim como a narrativa audiovisual a ser desenvolvida, por exemplo, são elaboradas a partir das interações em campo e não a partir de uma escolha determinada pelo pesquisador. Nesta perspectiva, o audiovisual não é mais entendido como um fato social e a experiência fílmica se torna o foco do processo, na medida em que remete a encontros entre pesquisadores e pesquisados, portanto, construindo múltiplas perspectivas e/ou vozes nas estratégias narrativas dos filmes (ALTMANN, 2009). Assim, as técnicas de coleta e de produção de material empírico na etnografia audiovisual constituem uma base para desenvolver modos mais eficazes de descrição, interação e análise das experiências de interseções culturais (ALTMANN, 2009).

Coautoria como via de sofisticação da narrativa. As abordagens participativas de produção dos filmes etnográficos se constituem com base no pressuposto de desconstrução da 'autoridade etnográfica' do pesquisador e na coautoria dos pesquisados. Coautoria implica em colaboração na produção audiovisual (vídeos participativos e colaborativos) e negociação na interpretação audiovisual (assistindo o filme como participante, gerando diálogo para dar sentido compartilhado ao material audiovisual). Nesse processo, os pesquisados se engajam colaborativamente na análise reflexiva e na interpretação, criando outras formas de conhecimento (COLLIER; WYER, 2016; COLLIER et al., 2015; IEDEMA et al., 2013). Ademais, a postura de coautoria do pesquisador permite o reconhecimento das diferentes narrativas dos 'nativos' na produção audiovisual. Permite, também, o entendimento dos diferentes campos de possibilidades que os 'leitores' dessa produção podem constituir, a partir de suas próprias práticas culturais. Nesse sentido, a lógica da coautoria proporciona um caminho para sofisticação da narrativa etnográfica.

O filme etnográfico baseado na coautoria produz eventos de comunicação nos quais o processo de codificação, utilizado durante a produção audiovisual, se combina ao ato de codificação da pesquisa etnográfica e o da decodificação (criação de sentido) realizado pelos pesquisados-espectadores (FRANZEN, 2013). O processo de observação participante deve possibilitar a identificação e o desenvolvimento das experiências sensoriais, particulares e subjetivas dos pesquisados que serão filmados durante a etnografia. Nesse processo, os 
pesquisados definem o que é importante para o registro audiovisual, bem como sua participação no processo de edição e de divulgação do resultado da pesquisa (FRANZEN, 2013).

Além disso, os pesquisados podem filmar, construir as narrativas e editar os filmes etnográficos (WILHOIT; KISSELBURGH, 2016). Nessa forma de participação, a etnografia é construída a partir de informações reflexivas, produzidas por meio de entrevistas e produção audiovisual de experiências reais da vida cotidiana dos pesquisados. Pesquisador e pesquisado, então, assistem os registros audiovisuais juntos: o pesquisado narra e explica as práticas sociais filmadas nos registros para, posteriormente, editarem (WILHOIT; KISSELBURGH, 2016).

Coautoria como experiência intercultural. Sob a égide da coautoria, a finalidade científica da produção audiovisual se congrega com as experiências interculturais dos pesquisados. Então, a prática entográfica passa a ser multifacetada ao incorporar diferentes tempos e linguagens e, consequentemente, produz outras estratégias narrativas que não somente a do pesquisador. As contradições e ambiguidades das interações culturais do trabalho de campo podem ser mais facilmente camufladas na construção do texto escrito, pela delimitação de fenômenos sociais. Todavia, essas contradições e ambiguidades ficam mais evidenciadas nos filmes etnográficos, pois este deixa de ser compreendido como pura ilustração ou mensagem para ser um artefato cultural polifônico, produzido no campo de pesquisa (ALTMANN, 2009).

Frente a artefatos socialmente construídos, o pesquisador precisa ser reflexivo em relação a como essas representações são construídas dentro do projeto participativo de pesquisa etnográfica, se questionando constantemente por que o registro audiovisual existe, quem o criou, qual é sua biografia (BANKS, 2001). Durante todo o processo da etnografia audiovisual participativa, serão coletados, de forma participativa, uma diversidade de materiais, a análise e estratégias de edição serão dialógicas e a criação de produtos (e.g. textos, vídeos, apresentações multimídia) que alcancem todo tipo de público. A interculturalidade que permeia esse processo se reflete em reflexividade de ambas as partes: pesquisador e pesquisado. Por exemplo, durante a edição pode ser adotada a técnica da edição dialética que propicia a criação de um texto mais colaborativo (FELD, 1987), baseado na negociação das representações etnográficas com os pesquisados quando as interpretações conflitam umas com as outras ou com aquela elaborada pelo pesquisador (GUBRIUM; HARPER, 2013).

A coautoria no processo etnográfico, situa o filme colaborativamente produzido como uma 'dádiva' entre pesquisador e pesquisado. 0 filme etnográfico expressa um espaço de compartilhamento reflexivo, onde reciprocidades, diálogos e trocas interculturais ocorrem. Deste modo, o roteiro do filme não é definido pelo etnógrafo, mas discutido e delineado, cotidianamente, pelas pessoas envolvidas na etnografia, à medida que os eventos ocorrem durante o trabalho de campo (OTTO, 2013).

Coautoria como engajamento social. Quando a etnografia audiovisual produz um filme etnográfico dentro da lógica da coautoria, este se torna uma estratégia de engajamento do público na realização da pesquisa e na divulgação dos resultados da pesquisa (FRANZEN, 2013). A etnografia audiovisual pode ser conduzida de forma a engajar os pesquisados, sendo mais acessível, inclusiva e visualmente atrativa, encorajando os membros da comunidade a refletir e engajar em debates sobre suas comunidades (GUBRIUM; HARPER, 
2016; GUBRIUM et al., 2015). Com efeito, o vídeo participativo (participatory video) é considerado com um dispositivo efetivo no desenvolvimento e transformação de indivíduos e comunidades, aprimorando o trabalho comunicacional de trabalhadores sociais, profissionais e sociólogos (WHITE, 2003). O engajamento social dos pesquisados se intensifica na medida em que a desconstrução da centralidade autoral do pesquisador ocorre.

O trabalho do antropólogo Jean Rouch nas décadas de 1950 e 1960 foi um dos primeiros experimentos etnográficos com uso audiovisual (GRIMSHAW, 2001; ROUCH, 2003; HEIDER, 2006). Rouch se engajou com a criação do filme como uma forma de 'antropologia compartilhada', em que o conhecimento de outra cultura deveria ser produzido de forma a ser compartilhado com os membros desta cultura. Rouch também foi reconhecido pela elaboração de filmagens participativas na forma de 'cinema verité', em que a filmagem detinha igual importância em relação ao resultado (filme), pois valoriza sobretudo o espaço para a reflexividade e o engajamento social das pessoas que se envolviam com o processo.

Ao realizar uma etnografia audiovisual com uma comunidade estigmatizada como sendo 'criminosa', Friedman (2013) afirma que o filme etnográfico deveria ser realizado com o entendimento dessa comunidade sobre os limites do quanto o filme deveria revelar sobre sua vida cotidiana. Então, a colaboração estreita na produção das narrativas do filme era a única maneira de engajar socialmente e eticamente os pesquisados para prosseguir com a pesquisa de campo (FRIEDMAN, 2013). Esta colaboração não só moldou o processo de filmagem, mas, também, se tornou um elemento importante da estrutura narrativa do filme, permitindo que os pesquisados definissem a estrutura e conteúdo do material audiovisual (FRIEDMAN, 2013). Esse tipo de engajamento socialmente colaborativo anima o processo de operacionalização do filme etnográfico, na atividade analítica, reflexiva e interpretativa, criando novas formas de conhecimento (COLLIER; WYER, 2016; COLLIER et al., 2015; IEDEMA et al., 2013).

Além do reconhecimento da importância dos pesquisados na construção das narrativas filmícas, a 'audiência' dos filmes também é fundamental na produção audiovisual do trabalho de campo. Aliás, quando o público possui um vínculo relacional com os pesquisados, o processo de divulgação do filme etnográfico reforça o engajamento social de todos envolvidos na promoção dos resultados da pesquisa etnografica (FRANZEN, 2013) e de sua interpretação. Por exemplo, ao apresentar o filme etnográfico sobre as benzedeiras para a comunidade onde o filme foi produzido, Braga (2012) destaca como o filme afetou as pessoas, despertando memórias sobre a região e motivando-as a serem mediadoras da construção de significados retratados no filme. Outro exemplo é da pesquisa de Connelly (2016). Ao discutir a recepção do filme etnográfico com residentes da Papoa Nova Guiné, entende que a recepção pela comunidade pesquisada é uma forma de 'repatriar' a pesquisa. A recepção pela comunidade que colaborou com etnografia audiovisual pode diferir da proposta original dos autores do filme (CONNELLY, 2016) e este material, ao ser disponibilizado para a comunidade, possibilita contínua releitura das práticas culturais pelos pesquisados. Com efeito, a etnografia audiovisual não é finalizada com a edição do filme e comentários da audiência. $O$ trabalho de pesquisa se extende à investigação dos efeitos produzidos pelo filme, especialmente pelas possíveis interpretações que os pesquisados construiram a partir dos resultados da pesquisa. Durante a apresentacão do filme etnográfico, os expectadores são impulsionados a protagonizarem o papel de mediadores (BRAGA, 2012). 
Coautoria como potencial de emancipação. Outra característica da coautoria na etnografia audiovisual é seu potencial de emancipação de todos envolvidos. As abordagens participativas emergem como resposta às críticas formuladas à etnografia tradicional, dentro do contexto tradicional da era colonial. São abordagens em que o encontro etnográfico é baseado em métodos segundo os quais pesquisador e pesquisados experimentam os eventos e se engajam no diálogo. Essa postura aflora o potencial emancipatório e humanista da etnografia ao reconhecer as compreensões vividas de outras pessoas no mundo contemporâneo. Dessa forma, essas abordagens contribuem para a edificação de um tipo de etnografia engajada com o espaço público, no qual os participantes podem refletir sobre questões cruciais de suas comunidades e assim se desenvolverem como cidadãos, ativistas e usuários de tecnologias (GUBRIUM; HARPER, 2016).

Os métodos colaborativos entorno da pesquisa audiovisual participativa tem início nas intervenções visuais (PINK, 2007), mas torna-se primordial para a organização de comunidades e políticas públicas (BIELLA, 2008). Registros audiovisuais não são registros neutros, mas uma representação politizada de artefatos, pessoas e eventos que explicam a sociedade e seus processos (BANKS, 2007). São fontes de poder e capital social, permitindo que grupos marginalizados possam transformar as representações dominantes e, com isso, se transformar. Aprender a produzir fotografias, filmes e mídias digitais pode ter efeitos emancipatórios em vários âmbitos e escalas sociais. Por exemplo, os índios Kayapos começaram a fazer seus próprios filmes na década de 1980 com a ajuda de antropólogos, o que conferiu visibilidade e status na mídia internacional (TURNER, 1992).

O filme etnográfico pode gerar oportunidades de empoderamento, mudança social e emancipação das pessoas pesquisadas pois suscita uma ordem relacional baseada na reflexividade (WHITING et al., 2018). Ele deve considerar as especificidades, práticas e problemas do contexto onde a pesquisa é realizada (FALZONE, 2004). Quando utilizado a partir de uma abordagem descentralizada, desregulamentada e cooperativa, a etnografia audiovisual cria um filme transcendente, que ajuda a membros de culturas em conflito encontrarem uma forma de compartilhar meta-culturas, criando narrativas colaborativas para redefinirem suas relações (FALZONE, 2004). A desregulamentação dos filmes possibilita transcender a 'busca pela verdade' na produção audiovisual, bem como transcender a primazia de critérios como validade, objetividade, confiabilidade e generalizabilidade, optando por critérios que incorporem as necessidades dos pesquisados, tais como empoderamento, democracia, eqüidade, libertação e liberdade de opressão (FALZONE, 2004).

A coautoria na etnografia audiovisual possibilita romper o distanciamento entre pesquisador e pesquisado, criando uma comunidade de 'participantes' na pesquisa, ao valorizar, especialmente a competência de reconhecimento dos pesquisados em relação à sua própria identidade (FALZONE, 2004). Por isso, a etnografia audiovisual possibilita a construção de identificações culturais compartilhadas entre diferentes comunidades, uma espécie de metacultura, em contextos de conflitos potenciais.

Práticas de coautoria. A coautoria da etnografia audiovisual envolve uma variedade de práticas de pesquisa. A prática ética se estabelece em quatro movimentos que o pesquisador deve realizar a todo momento: (a) o posicionamento da participação como uma raiz ética de pesquisa que encontra-se em constante diálogo, (b) o desenvolvimento de um plano de pesquisa que reconcilia objetivos acadêmicos com os objetivos dos pesquisados 
e com as normas éticas da colaboração, (c) a apresentação de resultados de pesquisa para um público acadêmico e para o público em geral, de forma a considerar o poder e a ética da representação, e (d) o controle e propriedade compartilhada do resultado da pesquisa, incluindo materiais visuais, políticas de intervenção, conhecimento acadêmico e planos para uma eventual colaboração futura.

Outras práticas podem animar o processo da etnografia audiovisual em comunidades: atividade de aquecimento, brainstorming, familiarização com a câmera filmadora, roteirização (esboço das sequências) da história, aprendizagem para operar a câmera filmadora, filmagem, reflexão sobre a filmagem e resultado da filmagem (MITCHELL, 2011). São práticas que requerem e reforçam o senso de construção social, de reflexividade, de coletividade, de convergência e de corporeidade (MITCHELL, 2011). Além dessas atividades, quando o filme é editado, inclui-se também o esboço da edição e a edição final do material. Nesse processo, algumas questões ajudam a melhor engajar os participantes (GUBRIUM; HARPER, 2016): todos serão ativos na produção do filme ou alguns servirão somente como conselheiros? Em que parte cada um dos participantes atuará no processo da pesquisa (e.g., objetivos do projeto, definição de público, roteirização, escrita de artigos)? Como a comunidade será definida em relação a sua identidade?

A prática das histórias digitais ajuda a reforçar o espírito de coautoria na etnografia audiovisual. Trata-se de narrativas curtas que criam histórias envolventes (LAMBERT, 2013). São histórias construídas a partir das posições subjetivas dos participantes e contadas como narrativas pessoais. 0 propósito é que cada pessoa pesquisada conte uma história que fale sobre suas próprias experiências. As oficinas de histórias digitais e seus resultados podem ser apreendidos pelo pesquisador como fonte preciosa para investigar os entendimentos socioculturais da experiência. As etapas das oficinas incluem aspectos como: 'obtendo suas ideias e emoções', 'encontrando o momento', 'vendo sua história', 'escutando sua história', 'articulando sua história', 'compartilhando sua história'. O processo e resultado da criação de histórias digitais oferecem um conjunto de materiais visuais, orais e textuais que são valiosos para alimentar a etnografia audiovisual. Na condição de artefatos do processo, as histórias digitais podem ser consideradas como terrenos para a produção e transformação de identidades individuais e coletivas (LAMBERT, 2013; GUBRIUM; HARPER, 2016).

Os arquivos digitais são práticas em que o pesquisador ou pesquisado digitaliza coleções e repertórios, disponibilizando-os, em seguida, para o público na internet. Essa mudança tecnológica ofere oportunidades para as pessoas pesquisadas participarem como consumidores, mas também como contribuidores e curadores. Arquivos constituem a fusão de artefatos com interpretação. O termo 'arquivos virtuais participativos' significa que usuários são encorajados a contribuir com artefatos (na forma de arquivos digitais) e interpretações sobre os materiais apresentados.

\section{DISCUSSÃO}

A primazia do audiovisual na cultura contemporânea. Os métodos audiovisuais são o conjunto de técnicas mais significantes na análise social do século XXI. Os avanços tecnológicos em equipamentos e edição reduziram custos e aumentaram a familiaridade dos usuários, mudando a produção e distribuição de filmes de uma atividade cara e profissional 
para uma atividade que pode ser realizada facilmente por estudantes e pesquisadores. A intensificação e popularização das mídias sociais, dos celulares, e de todas as múltiplas plataformas digitais, posiciona o audiovisual no coração da vida cultural contemporânea. Audiovisual refere-se tanto a vídeos compartilhados em uma base cotidiana entre amigos, quanto estratégias de organizações para construir sua cultura frente aos seus públicos, ou até formas de mobilização para a ação em movimentos sociais. O audiovisual é omnipresente na sociedade contemporânea e em suas organizações. Então, as etnografias audiovisuais não seriam uma alternativa metodológica apropriada e desejada para os tempos atuais?

Etnografias audiovisuais referem-se ao uso de tecnologias de registro para gravar imagens em movimento com som. Essas imagens são superiores as imagens estáticas. A compreensão da vida social é um processo social que acontece no decorrer do tempo. A melhor forma de coletar e comunicar informações não estáticas é aquela dos recursos audiovisuais. Na condição de etnógrafo audiovisual, o pesquisador dispõe de muito mais recursos e práticas para tomar decisões, do que um etnógrafo convencional que redige em cadernos de campo. O etnógrafo audiovisual tem que decidir o que, como e quando ver, ouvir e registrar. É necessário observar o mundo de perto e decidir se filmar e sobre o que filmar. $O$ etnógrafo audiovisual filma as ações e eventos ao seu redor, buscando sempre 0 melhor áudio, o melhor enquadramento e a melhor ação (LUFF; HEATH, 2012). Todavia, a preocupação do etnógrafo audiovisual é como praticar a coatuoria durante o processo de pesquisa, envolvendo e engajando todas as pessoas pesquisadas como protagonistas legítimas.

A etnografia audiovisual como engajamento público. O pesquisador que envereda pelo método da etnografia audiovisual dispõe de um universo de virtudes proporcionado por esse método, bem como desafios de muitas naturezas. Neste artigo, destacamos várias virtudes e desafios da mobilização da etnografia audiovisual na prática da pesquisa, além de termos contribuído para integrar as pesquisas e fornecer dois eixos que facilitam essa integração e aplicação do método pelos pesquisadores. No entanto, talvez uma das grandes virtudes e desafios seja trazer para o campo da Administração a prática da pesquisa como forma de engajamento público, como acontece na Sociologia. A etnografia audiovisual está relacionada ao engajamento público (SHRUM; CASTLE, 2014). Apesar de escrevermos majoritariamente em livros e artigos científicos, a maior parte das pessoas escutam e assistem, na maior parte do tempo. Ou seja, o público em geral estaria mais apto a ver um filme do que ler um artigo acadêmico. Muitas pessoas e comunidades no mundo não são letradas e isso não significa que sejam desinteressadas em entender sobre assuntos diversos. Um dos problemas de se disseminar o conhecimento somente por meio textual é que isso pode ser exclusivo e excludente. As metodologias audiovisuais podem contribuir para o sucesso do engajamento público em nossas áreas acadêmicas, pela linguagem audiovisual adaptada aos gostos e hábitos de consumo contemporâneo (SHRUM; CASTLE, 2014).

Desafios técnicos, teóricos e epistemológicos por trás da metodologia etnográfica. Muitos desafios emergem durante a etnografia audiovisual: o desafio de demonstrar domínio técnico sobre o uso do audiovisual durante a pesquisa e o desafio de alinhar o uso do audiovisual com teorias e epistemologias que sejam coerentes e potencializadoras de suas virtudes em relação à pesquisa. Ao fazer pesquisas em um ambiente mediado pelo registro audiovisual, somos convidados a desenvolver métodos mais inovadores e a rever o que costumamos mobilizar como categorias conceituais e analíticas. As etnografias audiovisuais 
nos instigam a explorar suas possibilidades, tanto para o processo de pesquisa, quanto na forma de autoria e na renovação de conceitos centrais nas Ciências Sociais e no campo da Administração. Ou seja, etnografias audiovisuais ultrapassam o que seria uma simples tradução de práticas tradicionais para meios audiovisuais de pesquisa. Emergem provocações na forma de diálogos entre teoria e etnografia, de parcerias entre pesquisador e pesquisados, em que práticas e conceitos antigos são revistos e atualizados. O filme etnográfico não é apenas um meio de registrar (coletar dados) o mundo sociocultural, mas uma prática metodológica para compreender e transformar o mundo.

O valor da etnografia audiovisual no terreno da Administração e dos Estudos Organizacionais. Apesar do uso de recursos audiovisuais na pesquisa organizacional estarem na moda, as etnografias audiovisuais são atípicas no campo da Administração e dos Estudos Organizacionais. As raras pesquisas existentes integram o audiovisual de forma processual e não envolvem os pesquisados na autoria da narrativa etnográfica (e.g. BARBOZA, 2017; HIETANEN, 2012; IEDEMA et al., 2006; LIU; MAITLIS, 2014; SLUTSKAYA et al., 2016; SMETS et al., 2014). Então, o terreno para o desenvolvimento de etnografias audiovisuais no campo da Administração e dos Estudos Organizacionais é amplo e fértil, apresentando alto potencial de contribuição, sobretudo quando pensamos em pesquisas que consigam integrar o audiovisual de forma mais integral e que envolvam plenamente os pesquisados como co-autores do processo de pesquisa.

O uso dos registros etnográficos no debate com as pessoas envolvidas no processo de pesquisa aprimora o entendimento da complexidade das práticas organizacionais e habilitam as pessoas a intervir nestas práticas (CARROLL et al., 2008). O audiovisual permite acessar conhecimentos que vão além das palavras, como os saberes tácitos, estéticos, sociomateriais e incorporados no âmbito organizacional (HINDMARSH; LLEWELLYN, 2018; SLUTSKAYA et al., 2016; TORALDO et al., 2016). A etnografia audiovisual, no campo da estratégia, tem o potencial de viabilizar uma análise mais detalhada das práticas estratégicas em seu contexto sociomaterial (VESA; VAARA, 2014). Nos Estudos Organizacionais, a etnografia audiovisual pode estimular a participação de grupos de difícil acesso, acessar melhor dimensões sensíveis do processo de organizar, melhorar a disseminação e relevância prática dos resultados da pesquisa (SLUTSKAYA et al., 2016).

No campo da Administracão e dos Estudos Organizacionais, as etnografias sempre ganharam destaque e valor pelas suas contribuições e por permitirem a geração de uma compreensão aprofundada do tópico pesquisado, além de promover múltiplas perspectivas e uma oportunidade para examinar processos (FINE et al., 2009) de forma mais robusta e fina. As contribuições fornecida pela várias etnografias organizacionais, ao longo do tempo, são consideráveis (FINE et al., 2009): a descoberta e elaboração das relações informais (WHYTE, 1948; BURAWOY, 1979; DALTON, 1959), o entendimento das organizações como sistemas de significados (BRESLER, 1997; KANTER, 1977; KUNDA, 1992; KOLB, 1983; STRAUSS, 1964), as relações entre organizações e seus ambientes (CARLILE, 2002; FINE, 1996; KILING; GERSON, 1977; PERLOW, 1997; POWELL, 1985), a dinâmica da mudança organizacional (BATE, 2000; BARLEY, 1986; PETTIGREW, 1985; VALLAS, 2003), o comportamento normativo e ética (ADLER, 1993; BECKER, 1963; JACKALL, 1988), questões de poder, política e controle nas organizações (BURAWOY, 1979; KONDO, 1990; PRASAD; PRASAD, 2000; PRATT, 2000; WEEKS, 2004), e marketing (BARBOZA, 2017; HIETANEN, 2012). As etnografias futuras, poderão dar continuidade a essa agenda 
de contribuição ao incorporarem o audiovisual em suas pautas temáticas, metodológicas e teóricas de pesquisa.

\section{CONCLUSÕES}

Nesta pesquisa, nosso ponto de partida foi a constatação da carência e da necessidade de obtermos infomações articuladas sobre as etnografias audiovisuais. 0 objetivo foi o de congregar o conhecimento acumulado sobre a relação entre etnografia e o universo do audiovisual, para que essa integração forneça horizontes metodológicos instigantes e viáveis para a pesquisa em Administracão e em Estudos Organizacionais.

A partir da análise sistemática de muitas produções acadêmicas no campo da metodologia de pesquisa, da Antropologia e da Sociologia, desenvolvemos e propomos dois eixos para pensarmos e aplicarmos a etnografia audiovisual no campo da Administração e dos Estudos Organizacionais. Os eixos devem orientar os pesquisadores a refletirem sobre como integrarem o audiovisual no processo etnografico e como lidarem com as questões de autoria. A integração pode ir de uma forma mais processual (periférica, o resultado da pesquisa ocorre na forma de texto: artigos, livros, capítulos de livro) ou integral (plena, o resultado da pesquisa ocorre na forma audiovisual: filmes etnográficos). A autoria varia de um envolvimento co-autoral ou não-autoral dos pesquisados no processo de pesquisa e na narrativa etnográfica, apesar de todos comungarem do princípio da descentralização da autoridade de autoria. Por meio da discussão desses dois eixos, apresentamos e discutimos vários potenciais e desafios relativos à adoção da etnografia audiovisual na prática da pesquisa.

Nossa expectativa é que o percurso deste artigo tenha contribuído para que o pesquisador organizacional possa vislumbrar a etnografia audiovisual como um caminho fecundo e viável de engajamento consciente em pesquisas futuras, entendendo que a linguagem audiovisual pode gerar possibilidades de inovação e ativação crítica, na medida em que encoraja o pesquisador a explorar novos formatos de produção, expressão e comunicação dos saberes científicos.

\section{AGRADECIMENTOS}

Agradecemos o apoio do CNPq (Conselho Nacional de Desenvolvimento Científico e Tecnológico, n. 400190/2016-8) e as sugestões enriquecedoras dos avaliadores.

\section{REFERÊNCIAS}

AARSAND, P.; FORSBERG, L. Producing children's corporeal privacy: ethnographic video recording as material-discursive practice. Qualitative Research, v. 10, n. 2, p. 249-268, 2010.

ADLER, P. A. Wheeling and Dealing: an Ethnography of an Upper-level Drug Dealing and Smuggling Community. New York: Columbia University Press, 1993. 
ALFONSO, A. I. et al (eds.). Working Images: Visual Research and Representation in Ethnography. New York: Routledgeed. 2004.

ALTMANN, E. Verdade, tempo e autoria: três categorias para pensar o filme etnográfco. Revista Anthropológicas, v. 20, n. 1/2, p. 57-79, 2009.

ALVESSON, M.; SKÖLDBERG, K. Reflexive methodology: new vistas for qualitative research. London: Sage Publications, 2000.

ASCH, T. The ethics of ethnographic film-making. In: CRAWFORD, P. I.; TURTON, D (eds.). Film as ethnography. Manchester: Manchester University Press, 1992.

BANKS, M. Using Visual Data in Qualitative Research. Thousand Oaks: Sage Publications, 2007.

. Visual Methods in Social Research. Thousand Oaks: Sage Publications, 2001. 1990.

Experience and reality in ethnographic film. Visual Sociology, v. 5, n. 2, p. 30-33,

BARBOZA, R. A. Vive la Révolution Animale! An Ethnography of the Social Consumer Movement of Vegetarianism. 2017. Tese (Doutorado). EAESP, Fundação Getúlio Vargas, São Paulo. 2017.

BARLEY, S. R. Technology as an Occasion for Structuring: Evidence from Observations of CT Scanners and the Social Order of Radiology Departments. Administrative Science Quarterly, v. 31, n. 1, p. 78-108, 1986.

BASIL, M. Use of photography and video in observational research. Qualitative Market Research: An International Journal, v. 14, n. 3, p. 246-257, 2011.

BATE, P. Changing the culture of a hospital: from hierarchy to networked community. Public Administration, v. 78, n. 3, p. 485-512, 2000.

BECKER, H. S. Outsiders. New York: The Free Press, 1963.

BELL, E.; DAVISON, J. Visual management studies: Empirical and theoretical approaches. International Journal of Management Reviews, v. 15, n. 2, p. 167-184, 2013.

BIELLA, P. Elementary forms of the digital media: tools for applied action research in visual anthropology. In: STRONG, M.; WILDER, L (ed.). Viewpoints: visual anthropologists at work. Austin: University of Texas Press, 2008. p. 363-388.

BLACK, S. P. Anthropological Ethics and the Communicative Affordances of Audio-Video Recorders in Ethnographic Fieldwork: Transduction as Theory. American Anthropologist, v. 119, n. 1, p. 46-57, 2017.

BRAGA, G. G. Por uma etnografia da recepção. Tessituras, v. 1, n. 1, p. 222-243, 2012.

BRESLER, R. A roupa surrada e o pai: etnografia em uma marcenaria. In: PRESTES MOTTA, F. C.; CALDAS, M. P (ed.). Cultura organizacional e cultura brasileira. São Paulo: Atlas, 1997.

BURAWOY, M. Manufacturing Consent: Changes in the Labor Process Under Monopoly Capitalism. Chicago: University of Chicago Press, 1979. 
CARLILE, P. R. A pragmatic view of knowledge and boundaries: boundary objects in new product development. Organization Science, v. 13, n. 4, p. 442-455, 2002.

CARROLL, K. et al. Reshaping ICU Ward Round Practices Using Video-Reflexive Ethnography. Qualitative Health Research, v. 18, n. 3, p. 380-390, 2008.

CARTA, S. Ethnographic film as filmic autobiography: David MacDougall's The Age of Reason. Visual Studies, v. 28, n. 1, p. 17-28, 2013.

CAVEDON, N. R. Fotoetnografia: a união da fotografia com a etnografia no descortinamento dos não-ditos organizacionais. Organizações \& Sociedade, v. 12, n. 35, p. 13-27, 2005.

CHIOZZI, P.; DRESNER, D. Reflections on ethnographic film with a general bibliography. Visual Anthropology, v. 2, n. 1, p. 1-84, 1989.

CHRISTIANSON, M. Mapping the Terrain: The Use of Video-Based Research in Top-Tier Organizational Journals. Organizational Research Methods, v. 21, n. 2, p. 261-287, 2018.

COELHO, R. F. Algumas notas sobre a história do cinema documentario etnográfico. Revista Comunicación, v. 10, n. 1, p. 755-766, 2012.

COLLIER, A. et al. The meaning of home at the end of life: A video-reflexive ethnography study. Palliative Medicine, v. 29, n. 8, p. 695-702, 2015.

COLLIER, A.; WYER, M. Researching Reflexively with Patients and Families: Two Studies Using Video-Reflexive Ethnography to Collaborate With Patients and Families in Patient Safety Research. Qualitative Health Research, v. 26, n. 7, p. 979-993, 2015.

CONGDON, E. L.; NOVACK, M. A.; GOLDIN-MEADOW, S. Gesture in Experimental Studies: How Videotape Technology Can Advance Psychological Theory. Organizational Research Methods, v. 21, n. 2, p. 489-499, 2018.

CONNELLY, A. J. Pikisi kwaiyai! (pictures tonight!): The screening and reception of ethnographic film in the Trobriand Islands, Papua New Guinea. The Australian Journal of Anthropology, v. 27, p. 3-29, 2016.

CORSARO, W. A. Something Old and Something New: The Importance of Prior Ethnography in the Collection and Analysis of Audiovisual Data. Sociological Methods Research, v. 11, n. 2, p. 145-166, 1982.

CRAWFORD, P. I.; TURTON, D (eds.). Film as ethnography. Manchester: Manchester University Pressed. 1992.

DALTON, M. Men who Manage: Fusions of Feeling and Theory in Administration. New York: John Wiley \& Sons, 1959.

DICKS, B. et al. Multimodal ethnography. Qualitative Research, v. 6, n. 1, p. 77-96, 2006.

ERICKSON, F. Uses of video in social research: a brief history. International Journal of Social Research Methodology, v. 14, n. 3, p. 179-189, 2011.

Audiovisual records as a primary data source. Sociological Methods and Research,

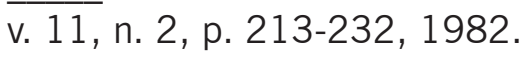

FALZONE, P. Transcendent Ethnography: Designing an Action Research Approach to Ethnographic Film within Cultures of Conflict. Action Research, v. 2, n. 3, p. 326-344, 2004. 
FELD, S. Dialogic editing: interpreting how Kaluli read sound and sentiment. Cultural Anthropology, v. 2, n. 2, p. 190-210, 1987.

FELE, G. The use of video to document tacit participation in an emergency operations centre. Qualitative Research, v. 12, n. 3, p. 280-303, 2012.

FERRAZ, A. L. M. C. Uma heurística do filme etnográfico: em torno de imagem, rememoração e presença. Etnográfica, v. 18, n. 3, p. 575-598, 2014.

FIJN, N. Filming the Significant Other: Human and Non-Human. Asia Pacific Journal of Anthropology, v. 8, n. 4, p. 297-307, 2007.

FINE, G. A. Kitchens: the Culture of Restaurant Work. Berkeley: University of California Press, 1996.

. et al. Ethnography in organizational settings. In: BUCHANAN, D. A.; BRYMAN, A (Ed.). The SAGE Handbook of Organizational Research methods. Los Angeles: Sage Publications, 2009.

FLECK, J. P. D. S.; ROSSI, C. A. V. Vinileiros: a vídeo-etnografia do colecionador de vinil. lluminuras, v. 10, n. 23, p. 1-16, 2009.

FONSECA, C. et al. Nos bastidores de um vídeo etnográfico. In: FELDMAN-BIANCO, B.; LEITE, M. L. M (eds.). Desafios da Imagem: Fotografia, Iconografia e Vídeo nas Ciências Sociais. Campinas: Papirus, 1998.

FRANZEN, S. Engaging a specific, not general, public: the use of ethnographic film in public scholarship. Qualitative Research, v. 13, n. 4, p. 414-427, 2013.

FRIEDMAN, K. Collaboration against ethnography: How colonial history shaped the making of an ethnographic film. Critique of Anthropology, v. 33, n. 4, p. 390-411, 2013.

GARRETT, B. Videographic geographies: Using digital video for geographic research. Progress in Human Geography, v. 35, n. 4, p. 512-541, 2010.

GILlETTE, M. B. New Ethnographic Film in the New China. Visual Anthropology Review, v. 30, n. 1, p. 1-10, 2014.

GOODMAN, P. S. Filmmaking and Research: An Intersection. Journal of Management Inquiry, v. 13, n. 4, p. 324-335, 2004.

GRIMSHAW, A. The Ethnographer's Eye: Ways of Seeing in Anthropology. Cambridge: Cambridge University Press, 2001.

GRIMSHAW, A.; RAVETZ, A. Drawing with a camera? Ethnographic film and transformative anthropology. Journal of the Royal Anthropological Institute, v. 21, p. 255-275, 2015.

GUBRIUM, A.; HARPER, K. Participatory Visual and Digital Methods. New York: Routledge, 2013.

GUBRIUM, A. et al (eds.). Participatory Visual and Digital Research in Action. London: Routledge, 2015.

GYLFE, P. et al. Video methods in strategy research: Focusing on embodied cognition. Strategic Management Journal, v. 37, n. 1, p. 133-148, 2016. 
HASSARD, J. Researching work and institutions through ethnographic documentaries. In: BUCHANAN, D. A.; BRYMAN, A (eds.). The SAGE Handbook of Organizational Research Methods. Los Angeles: Sage Publications, 2009.

HASSARD, J.; BUCHANAN, D. A. From Modern Times to Syriana: Feature Films as Research Data. In: BUCHANAN, D. A.; BRYMAN, A (eds.). The SAGE Handbook of Organizational Research Methods. Los Angeles: Sage Publications, 2009.

HEATH, C.; LUFF, P. The Naturalistic Experiment: Video and Organizational Interaction. Organizational Research Methods, v. 21, n. 2, p. 466-488, 2018.

HEIDER, K. G. Ethnographic Film. Austin: University of Texas Press, 2006.

HENLEY, P. Ethnographic film: Technology, practice and anthropological theory. Visual Anthropology, v. 13, n. 2, p. 207-226, 2000.

HIETANEN, J. Videography in Consumer Culture Theory: An Account of Essence(s) and Production. 2012. Tesis (Ph.D.) - School of Economics, Aalto University, Helsinki, 2012.

HINDMARSH, J.; HEATH, C. Video-Based Studies of Work Practic. Sociology Compass, v. 1, n. 1, p. 156-173, 2007.

HINDMARSH, J.; LLEWELLYN, N. Video in Sociomaterial Investigations: A Solution to the Problem of Relevance for Organizational Research. Organizational Research Methods, v. 21, n. 2, p. 412-437, 2018.

HOR, S.-Y. et al. Creating spaces in intensive care for safe communication: a video-reflexive ethnographic study. BMJ Quality \& Safety, v. 23, n. 12, p. 1007-1013, 2014.

HUTCHISON, K. Homework through the Eyes of Children: what does visual ethnography invite us to see? European Educational Research Journal, v. 10, n. 4, p. 545-558, 2011.

IEDEMA, R. et al. Visibilising clinical work: Video ethnography in the contemporary hospital. Health Sociology Review, v. 15, n. 2, p. 156-168, 2006.

IEDEMA, R. MESMAN, J.; CARROLL, K. E. Visualising Health Care Improvement. Abingdon: Radcliffe Publishing Ltd, 2013.

ISAACS, E.; SZYMANSKI, M. H. Capturing Mobile Telepresence through Logging and Video Shadowing: A Two-phase Study Design. Field Methods, v. 25, n. 3, p. 299-315, 2013.

JACKALL, R. Moral Mazes: the World of Corporate Managers. Oxford: Oxford University Press, 1988.

JACKSON JR, J. L. An Ethnographic Filmflam: Giving Gifts, Doing Research, and Videotaping the Native Subject/Object. American Anthropologist, v. 106, n. 1, p. 32-42, 2004.

JARRETT, M.; LIU, F. "Zooming With": A Participatory Approach to the Use of Video Ethnography in Organizational Studies. Organizational Research Methods, v. 21, n. 2, p. 412-437, 2018.

KANTER, R. M. Men and Women of the Corporation. New York: Basic Books, 1977.

KILING, R.; GERSON, E. The social dynamics of technical innovations in the computing world. Symbolic interaction, v. 1, p. 132-146, 1977. 
KNOBLAUCH, H.; SCHNETTLER, B. Videography: analysing video data as a 'focused' ethnographic and hermeneutical exercise. Qualitative Research, v. 12, n. 3, p. 334-356, 2012. KOLB, D. M. The Mediators. Cambridge: MIT Press, 1983.

KONDO, D. K. Crafting Selves: Power, Gender, and Discourses of Identity in a Japanese Workplace. Chicago: University of Chicago Press, 1990.

KUNDA, G. Engineering Culture: Control and Commitment in a High-tech Corporation. Philadelphia: Temple University Press, 1992.

LAMBERT, J. Digital Storytelling: Capturing Lives, Creating Communities. New York: Routledge, 2013.

LEBARON, C. et al. An Introduction to Video Methods in Organizational Research. Organizational Research Methods, v. 21, n. 2, p. 239-260, 2018.

LEVIN, M.; CRUZ, A. D. Behind the Scenes of a Visual Ethnography: A Dialogue between Anthropology and Film. Journal of Film and Video, v. 60, n. 2, p. 59-68, 2008.

LIU, F.; MAITLIS, S. Emotional Dynamics and Strategizing Processes: A Study of Strategic Conversations in Top Team Meetings. Journal of Management Studies, v. 51, n. 2, p. 202234, 2014.

LOIZOS, P. Innovation in Ethnographic Film: From Innocence to Self-consciousness, 195585. Chicago: The University of Chicago Press, 1993.

LUFF, P.; HEATH, C. Some 'technical challenges' of video analysis: social actions, objects, material realities and the problems of perspective. Qualitative Research, v. 12, n. 3, p. 255-279, 2012.

MACDOUGALL, D. Ethnographic film: failure and promise. Annual Review of Anthropology, v. 7, p. 405-425, 1978.

MARKS, D. Ethnography and Ethnographic Film: From Flaherty to Asch and after. American Anthropologist, v. 97, n. 2, p. 339-347, 1995.

MENGIS, J. et al. The Video Production of Space: How Different Recording Practices Matter. Organizational Research Methods, v. 7, p. 1-28, 2016.

MEYER, R. E. et al. The Visual Dimension in Organizing, Organization, and Organization Research: Core Ideas, Current Developments, and Promising Avenues. Academy of Management Annals, v. 7, n. 1, p. 489-555, 2013.

MITCHELL, C. Doing Visual Research. Los Angeles: Sage Publications, 2011.

MURTHY, D. Digital Ethnography: An Examination of the Use of New Technologies for Social Research. Sociology, v. 42, n. 5, p. 837-855, 2008.

NASCIMENTO, C. R. Etnografia Fílmica: Lugares, corpos e subjetividades nas cenas de Amarelao Manga. Revista Extensão em Debate, v. 2, p. 1-15, 2015.

NAVAJAS, J. et al. The limits of the photographic act as a metaphor for the assessment of organizational culture. An ethnographic study of a high reliability organization. Safety Science, v. 59, p. 116-125, 2013. 
OTTO, T. Ethnographic Film as Exchange. Asia Pacific Journal of Anthropology, v. 14, n. 2, p. 195-205, 2013.

PERLOW, L. A. Finding Time: How Corporations, Individuals, and Families can Benefit from New Work Practices. Ithaca: ILR Press, 1997.

PETTIGREW, A. The Awakening Giant: Continuity and Change in ICl. Oxford: Basil Blackwell, 1985.

PINK, S. et al. Digital Ethnography: Principles and Practice. London: Sage Publications, 2016.

. Researching in atmospheres: video and the 'feel' of the mundane. Visual Communication, v. 14, n. 3, p. 351-369, 2014.

PINK, S. Doing Visual Ethnography. London: Sage Publications, 2007.

. More visualising, more methodologies: on video, reflexivity and qualitative research. The Sociological Review, v. 49, n. 4, p. 586-599, 2001.

POWELL, W. W. Getting into Print: the Decision-making Process in Scholarly Publishing. Chicago: Chicago University Press, 1985.

PRASAD, P.; PRASAD, A. Stretching the Iron Cage: The Constitution and Implications of Routine Workplace Resistance. Organization Science, v. 11, n. 4, p. 384-403, 2000.

PRATT, M. G. The good, the bad, and the ambivalent: managing identification among Amway distributors. Administrative Science Quarterly, v. 45, p. 456-493, 2000.

RAKIC, T.; CHAMBERS, D. Researcher with a movie camera: visual ethnography in the field. Current Issues in Tourism, v. 12, n. 3, p. 255-270, 2009.

ROBBENS, A. C. G. Sensorial fieldwork. In: ROBBENS, A. C. G.; SUKA, J. A (eds.). Ethnographic Fieldwork: An Anthropological Reader. Malden: Blackwell Publishing, 2007.

ROUCH, J. Ciné-ethnography. Minneapolis: University of Minnesota Press, 2003.

RUBY, J. A Future for Ethnographic Film? Journal of Film and Video, v. 60, n. 2, p. 5-14, 2008.

. The last 20 years of visual anthropology: a critical review. Visual Studies, v. 20, n. 2, p.159-170, 2005.

RUSSELL, C. Experimental Ethnography: the Work of Film in the Age of Video. Durham: Duke University Press, 1999.

SHRUM, W. M.; CASTLE, L. Visionary sociology: problems of public sociology and audiovisual solutions. American Sociologist, v. 45, n. 5, p. 412-431, 2014.

SHRUM, W. M.; SCOTT, G. S. Video Ethnography in Practice: Planning, Shooting, and Editing for Social Analysis. Thousand Oaks: Sage Publications, 2017.

SILVA, S. J. D. Luzes, câmera, colonialismo: colonialismo, filme etnográfico e antropologia.

SINAIS - Revista Eletrônica de Ciências Sociais, v. 1, n. 2, p. 31-46, 2007. 
SLUTSKAYA, N. et al. Better Together: Examining the Role of Collaborative Ethnographic Documentary in Organizational Research. Organizational Research Methods, v. 21, n. 2, p. 341-365, 2018.

SMETS, M. et al. Charting new territory for organizational ethnography: Insights from a team-based video ethnography. Journal of Organizational Ethnography, v. 3, n. 1, p. 10-26, 2014.

STRAUSS, A. L. et al. Psychiatric ideologies and institutions. Glencoe: Free Press, 1964.

TORALDO, M. L. et al. Modes of Knowing: Video Research and the Problem of Elusive Knowledges. Organizational Research Methods, v. 21, n. 2, p. 438-465, 2018.

TURNER, T. Defiant images: the Kayapo Appropriation of video. Anthropology Today, v. 8 , n. 5-15, 1992.

VALLAS, S. P. Why teamwork fails: obstacles to workplace change in four manufecturing plants. American Sociological Review, v. 68, n. 2, p. 223-250, 2003.

VESA, M.; VAARA, E. Strategic ethnography 2.0: Four methods for advancing strategy process and practice research. Strategic Organization, v. 12, n. 4, p. 288-298, 2014.

WEEKS, J. Unpopular Culture: the Ritual of Complaint in a British bank. Chicago: Chicago University Press, 2004.

WHITE, S. A (ed.). Participatory Video: Los Angeles: Sage Publications, 2003.

WHITING, R. et al. Who's Behind the Lens?: A Reflexive Analysis of Roles in Participatory Video Research. Organizational Research Methods, v. 21, n. 2, p. 316-340, 2018.

WHYTE, W. F. Human Relations in the Restaurant Industry. New York: McGraw-Hill, 1948.

WILHOIT, E. D.; KISSELBURGH, L. G. Through the Eyes of the Participant: Making Connections between Researcher and Subject with Participant Viewpoint Ethnography. Field Methods, v. 28, n. 2, p. 208-226, 2016.

ZUNDEL, M. et al. The Utility of Video Diaries for Organizational Research. Organizational Research Methods, v. 7, p. 1-26, 2016.

Data de Submissão: 11/12/2018.

Data de Aprovação: 17/06/2019. 